\title{
Physiological roles of regulated Ire1 dependent decay
}

\section{Dina S. Coelho and Pedro M. Domingos*}

Instituto de Tecnologia Química e Biológica, Universidade Nova de Lisboa, Oeiras, Portugal

\section{Edited by: \\ Kezhong Zhang, Wayne State \\ University, USA}

\section{Reviewed by:}

Daochun Sun, University of Texas Southwestern Medical Center at Dallas, USA

Santiago Schnell, University of Michigan Medical School, USA

Zeng-quan Yang, Wayne State

University, USA

\section{${ }^{*}$ Correspondence}

Pedro M. Domingos, Instituto de Tecnologia Química e Biológica,

Universidade Nova de Lisboa, Avenida da República, 2780-157 Oeiras,

Portugal

e-mail:domingp@itqb.unl.pt
Inositol-requiring enzyme 1 (Ire1) is an important transducer of the unfolded protein response (UPR) that is activated by the accumulation of misfolded proteins in the endoplamic reticulum (ER stress). Activated Ire1 mediates the splicing of an intron from the mRNA of Xbp1, causing a frame-shift during translation and introducing a new carboxyl domain in the Xbp1 protein, which only then becomes a fully functional transcription factor. Studies using cell culture systems demonstrated that Ire1 also promotes the degradation of mRNAs encoding mostly ER-targeted proteins, to reduce the load of incoming ER "client" proteins during ER stress. This process was called RIDD (regulated Ire1-dependent decay), but its physiological significance remained poorly characterized beyond cell culture systems. Here we review several recent studies that have highlighted the physiological roles of RIDD in specific biological paradigms, such as photoreceptor differentiation in Drosophila or mammalian liver and endocrine pancreas function. These studies demonstrate the importance of RIDD in tissues undergoing intense secretory function and highlight the physiologic role of RIDD during UPR activation in cells and organisms.

\section{Keywords: Ire1, Xbp1, RIDD, endoplasmic reticulum stress, unfolded protein response}

\section{ENDOPLASMIC RETICULUM STRESS AND THE UNFOLDED PROTEIN RESPONSE}

The endoplasmic reticulum (ER) is the entry site for the secretory pathway; all proteins targeted to the plasma membrane, extracellular space, and some organelles are translated into the ER, where they are folded and modified (Cooper, 2000). Proteins that fail to fold into their native conformation are targeted for ER-associated degradation (ERAD). Proteins marked as terminally misfolded are dislocated to the cytoplasm, where they are degraded by the ubiquitin-proteasome system (Smith et al., 2011; Claessen et al., 2012).

A number of cellular stress conditions such as low glucose levels, redox stress, or abnormal ER calcium content may perturb protein maturation in the ER or interfere with the capacity of the folding machinery in the ER (Marciniak and Ron, 2006). Many physiological processes may further challenge the ER by imposing suddenly large amounts of "client" proteins (Moore and Hollien, 2012). The imbalance between the ER folding capacity and the burden of incoming proteins may lead to the accumulation of misfolded proteins, causing ER stress. Adaptation to ER stress is mediated by the unfolded protein response (UPR; Ron and Walter, 2007; Hetz, 2012; Gardner etal., 2013). The UPR is a collection of integrated signaling pathways activated by ER-localized transmembrane protein sensors, which have luminal domains that detect misfolded proteins in the ER and cytoplasmatic effector domains that transduce signaling to the transcriptional and/or translational apparatus.

The UPR was first described in budding yeast, where it is represented by a single linear pathway (Mori etal., 1992). In higher eukaryotes the UPR is more complex and is mediated by three ER transmembrane sensors: pancreatic ER kinase (PKR)-like
ER kinase (PERK), activating transcription factor 6 (ATF6), and inositol-requiring enzyme 1 (Ire1; Harding et al., 2002). The UPR outcomes are temporally coordinated: first, translation is attenuated to reduce the load of proteins into the ER; second, genes encoding ER chaperones and enzymes are up-regulated to increase the ER folding capacity; and third, genes encoding ERAD components are induced to enhance degradation of misfolded proteins from the ER.

If the mechanisms activated by the UPR are insufficient to decrease ER stress and restore ER homeostasis, cells may undergo apoptosis (Rasheva and Domingos, 2009). Chronic ER stress and defective activation of the UPR have been involved in the pathology of several human diseases, such as cancer, diabetes, neurodegenerative disorders, and chronic inflammation (Wang and Kaufman, 2012). Therefore, there has been increasing interest in controlling the ER stress pathways and discover new therapeutic targets to treat these diseases.

\section{Ire1 SIGNALING}

Being the most evolutionarily conserved arm of the UPR, Ire1 is a type I ER-resident transmembrane protein with a ER luminal dimerization domain and a cytoplasmic domain with Ser/Thr kinase and endoribonuclease activities (Figure 1; Cox et al., 1993; Mori et al., 1993; Shamu and Walter, 1996; Tirasophon et al., 1998; Wang et al., 1998; Liu et al., 2000; Koizumi et al., 2001; Shen et al., 2001; Korennykh and Walter, 2012).

In the budding yeast the only known substrate of Ire 1 is the mRNA of the bZIP transcription factor Hacl (Cox and Walter, 1996; Mori et al., 1996; Nikawa et al., 1996). In case of ER stress, Ire1 associates in oligomers after Binding immunoglobulin protein (BiP) release and activates its RNase domain by autophosphorylation (Shamu and Walter, 1996; Welihinda and Kaufman, 1996; 


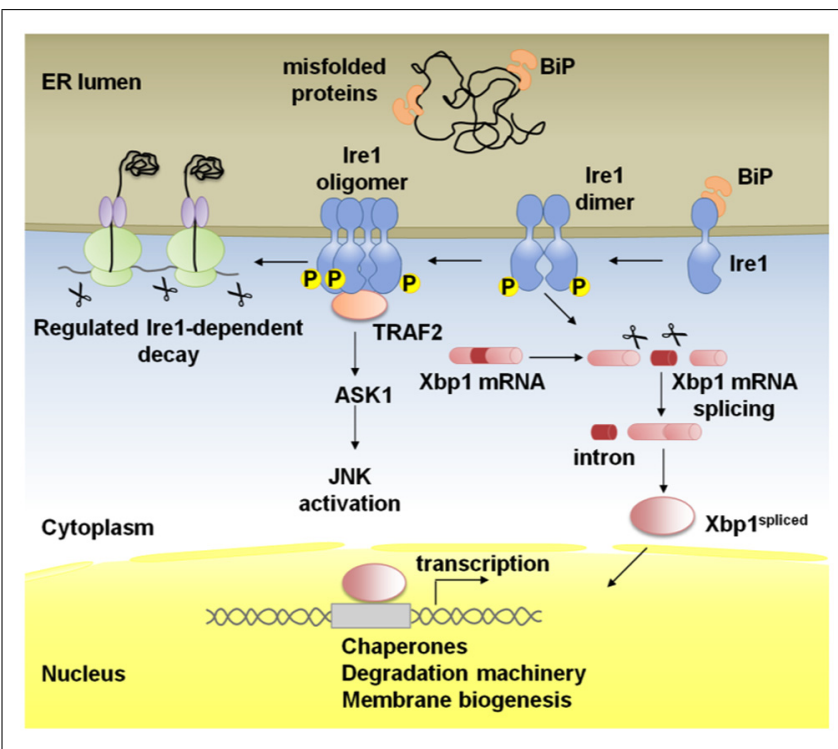

FIGURE 1 | Schematic representation of Ire1 signaling. Binding

immunoglobulin protein (BiP) binds Ire1 luminal domain and maintains it in a monomeric inactive form. In stressed cells, BiP is recruited to misfolded proteins and Ire 1 is activated following conformational changes induced by dimerization of monomers in the plane of the membrane and

trans-autophosphorylation. Higher order oligomers, which might form upon additional stress stimuli, reinforce Ire1 RNase activity. Activated Ire1 mediates the splicing of Xbp1 mRNA in higher eukaryotes (or Hac1 in yeast). Splicing of the intron from the Xbp1 transcript results in a

frame-shift and the production of a potent transcription factor, Xbp1-spliced, that regulates many UPR target genes to promote protein folding in the ER lumen, ER-associated degradation (ERAD) of misfolded proteins and ER biogenesis. Ire1 can also act by alternative pathways; phosphorylated Ire1 associates with TRAF2 and activates the JNK pathway via ASK1. In the regulated Ire1 dependent decay (RIDD) pathway, Ire1 degrades mRNAs localized to the ER membrane through its RNase activity leading to a reduction in the amount of proteins imported into the ER lumen.

Liu et al., 2000; Papa et al., 2003; Lee et al., 2008; Korennykh et al., 2009, 2011a). Activated Ire1 recognizes a double stem loop flanking a 252bp intron in Hacl mRNA and cleaves it twice (Sidrauski and Walter, 1997; Korennykh et al., 2011b), while a transfer RNA ligase joins the exons (Sidrauski et al., 1996). This Ire1-mediated unconventional splicing event releases the translational repression exerted by the $252 \mathrm{bp}$ intron and allows the $\mathrm{Hacl}^{\text {spliced }}$ protein to act as a transcription factor (Chapman and Walter, 1997; Rüegsegger et al., 2001). The functional homolog of Hacl in mammals is Xbp1 (Yoshida et al., 2001; Calfon et al., 2002), which is also only active as a transcription factor after the Ire1-mediated splicing of the $\mathrm{Xbp} 1 \mathrm{mRNA}$. In this case, however, $\mathrm{Xbp} 1^{\text {unspliced }}$ is translated and originates a protein that is rapidly degraded (Calfon et al., 2002; Yoshida et al., 2006).

Genetic profiling and analyses revealed that Hac1/Xbp1 control the expression of genes related to the UPR including chaperone induction, up-regulation of ERAD machinery, membrane biogenesis, and ER quality control (Lee et al., 2003; Shaffer et al., 2004; Shoulders et al., 2013). In mammals, Xbp1 also activates the expression of cell type specific targets linked to cell differentiation, signaling, and DNA damage (Acosta-Alvear et al., 2007; Lee et al., 2003).

\section{TARGETING OF mRNAs TO Ire1}

The mechanism of recruitment of Hac1/Xbp1 mRNAs to the ER membrane seems to differ considerably between yeast and mammals. Under non-stressed conditions, unspliced Hacl mRNA is found mostly in the cytoplasm, in association with stalled ribosomes. Upon ER stress, Hacl mRNA is recruited to Irel clusters in the ER membrane, in a process that depends on translational repression and on a bipartite element (BE) present at the $3^{\prime}$ untranslated region of the Hacl mRNA (Aragón et al., 2009).

In mammals, the Xbp1 $1^{\text {unspliced }}$ mRNA is translated under normal conditions and originates a protein that associates with membranes via two hydrophobic regions (HR1 and HR2). The HR2 is a conserved region predicted to form a $\alpha$-helix that has propensity to interact with the lipid bi-layer of the membrane (Yanagitani et al., 2009, 2011). Presumably, upon Xbp1 mRNA translation, HR1 and HR2 on the nascent polypeptide associate with the ER membrane and bring the Xbp1 mRNA-ribosomenascent chain (RNC) complex to the vicinity of Ire1, facilitating Ire1-mediated splicing of Xbp1 mRNA.

\section{Xbp1 INDEPENDENT FUNCTIONS OF Ire1}

Non-overlapping defects in Ire1 or Xbp1 mutant Caenorhabditis elegans first supported the existence of alternative roles for Ire1, besides Xbp1 mRNA splicing (Shen etal., 2005). Ire1 is thought to regulate apoptosis, autophagy, and ERAD through interaction with cytoplasmic partners independently of its RNase activity (Hetz and Glimcher, 2009). The cytosolic domain of Ire1 interacts with Traf2 (TNFR-associated factor 2) and activates ASK1 (Apoptosis signal-regulating kinase 1), triggering the JNK (cJun-N terminal kinase) pathway (Urano etal., 2000; Nishitoh etal., 2002). This Ire1/Traf2 interaction may lead to the activation of apoptosis under irreversible ER stress (Mauro etal., 2006). Ire1 may also control levels of autophagy under ER stress through activation of the JNK pathway (Ogata et al., 2006). The phosphorylation of the antiapoptotic BCL2 at the ER by JNK stimulates autophagy by modulating the activity of Beclin1. Dissociation of the complex formed by BCL2 and Beclin1 induces autophagy (Pattingre et al., 2009).

The cytoplasmic domain of unphosphorylated (inactive) Ire1 physically interacts with the ubiquitin specific protease 14 (USP14), and this association is inhibited by ER stress and Ire1 activation (Nagai etal., 2009). USP14, which is recruited to the ERAD machinery via interaction with Ire $1 \alpha$, inhibits ERAD through a deubiquitination-independent mechanism (Nagai et al., 2009). Finally, non-muscle myosin IIB interacts with Ire1 during ER stress, revealing that interaction of Ire1 with the cytoskeleton is required for optimal regulation of Irel activity (He et al., 2012).

\section{REGULATED Ire1-DEPENDENT DECAY (RIDD)}

A breakthrough report uncovered that the Ire1 RNase has broad range of mRNA substrates besides Xbp1 mRNA in Drosophila S2 cells. The group of Jonathan Weissman found through gene profiling experiments that a subset of mRNAs are degraded during ER stress by a mechanism that is dependent on Ire1 but not Xbp1 (Hollien and Weissman, 2006). The degraded mRNAs encoded mostly proteins with signal peptide/transmembrane domains that 
would represent an additional challenge to the ER folding machinery under ER stress. This mechanism was named RIDD, for Regulated Ire1-Dependent Decay, and was later also described in mammalian cells and in the fission yeast (which lacks any Hac1/Xbp1 homolog; Hollien etal., 2009; Cross etal., 2012; Kimmig et al., 2012). While in Drosophila S2 cells RIDD downregulates many RNAs by $5-10$ fold, in mammals the magnitudes of the changes in expression were smaller, twofold or less for many targets (Hollien and Weissman, 2006; Hollien et al., 2009).

The mechanism of targeting mRNAs to RIDD seems to have diverged throughout evolution (Hollien, 2013). In Drosophila S2 cells, RIDD has a broad scope of targets and there is a strong correlation between interaction of a mRNA with the ER membrane and the extension of its degradation by RIDD (Hollien and Weissman, 2006; Gaddam et al., 2013). In fact, deletion of the signal peptide from a known RIDD target prevents its degradation and conversely, addition of a signal peptide to GFP is sufficient to promote its degradation by RIDD. One interesting exception is the mRNA of PlexinA, which is strongly associated with the ER membrane, but it is protected from RIDD and is continuously translated, even during ER stress (Gaddam et al., 2013). PlexinA mRNA has regulatory upstream ORFs, which are necessary for its protection from RIDD. Another interesting exception is the mRNA encoding Smt3, a homolog of SUMO (small ubiquitin-like modifier), which is cleaved by RIDD on a stem loop structure, despite not being stably associated to the ER membrane (Moore et al., 2013).

In mammalian cells, RIDD targets are enriched for mRNAs containing a cleavage site with a consensus sequence (CTGCAG) and a predicted secondary structure similar to the conserved Ire1 recognition stem-loop of the Xbp1 mRNA (Han et al., 2009; Oikawa et al., 2010; Hur et al., 2012). Deletion of the stem-loop or mutagenesis of the conserved bases abrogated RIDD (Oikawa et al., 2010).

\section{PHYSIOLOGICAL RELEVANCE OF RIDD}

The physiological relevance of RIDD has been recently demonstrated in several different biological models, with specific cellular and/or developmental conditions. RIDD has a role controlling the expression of lipogenic enzymes and modulating levels of lipids in the serum. Ire1 $\beta$, which is specifically expressed in the epithelial cells of the gastrointestinal tract, has a protective role against hyperlipidemia in mice fed with a high fat or high cholesterol diet by decreasing the absorption of lipids in the intestine (Iqbal et al., $2008)$. Ire $1 \beta$ promotes the post-transcriptional degradation of the ER chaperone microsomal triglyceride transfer protein (MTP), involved in the assembly of apolipoproteins B and biosynthesis of chylomicrons (Iqbal et al., 2008). In the liver, Xbp1 deficiency provokes Ire $1 \alpha$ hyperactivation, which contributes to a hypolipogenic phenotype in mice characterized by reduced plasma cholesterol and triglycerides (So et al., 2012). A comprehensive comparative microarray analysis identified 112 genes induced by Ire $1 \alpha$ siRNA treatment in Xbp1-deficient mice. Among these genes are the ones encoding Angiopoietin-like protein 3 (Angptl3) and ces1 genes, which are involved in lipid metabolism and were further validated as RIDD substrates (So et al., 2012). The targeting of $\mathrm{Xbp} 1$ may be a therapeutic approach in dyslipidemic diseases, as
Xbp1 deficiency in the liver, in leptin-deficient ob/ob mice, lowers hepatic triglycerides and plasma cholesterol levels (So et al., 2012).

Ire1 $\beta$ was also found to have a homeostatic role in the secretory goblet cells of the intestine through the down-regulation of mRNA levels of the major secretory product mucin 2 (Tsuru et al., 2013). The knock-out of Ire1 $\beta$ isoform in mouse colon results in disorganization of the ER in the goblet cells at early stages of maturation with accumulation of a precursor form of mucin 2 in the expanded ER lumen and induction of ER stress. Remarkably, Ire $1 \alpha$ seems to have a distinct role in goblet cells mediating Xbp 1 splicing and promoting the activation of UPR targets like BiP (Tsuru et al., 2013). Ire $1 \alpha$ has a protective role in rodents against the liver damage caused by an overdose of the analgesic drug acetaminophen through the degradation of the mRNA of two P450 enzymes, Cypla2 and Cyp2e1, that are responsible for metabolizing the drug into a cytotoxic metabolite (Hur et al., 2012). Again, hyperactivation of Ire $1 \alpha$, caused by the liver specific deletion of Xbp1, prevents prolonged JNK activation and improves the morphology of the liver in mice injected with acetaminophen (Hur et al., 2012).

Several studies demonstrate that Ire $1 \alpha$ plays an important role regulating pancreatic $\beta$-cells homeostasis by controlling the levels of insulin synthesized in the ER. Treatment of $\beta$ cells with high levels of glucose hyperactivates Ire1, which correlates with a decrease of insulin mRNA expression (Lipson et al., 2008). Later, Ire 1 was shown to cleave Insulin 1 and Insulin 2 mRNAs at specific sites in vitro (Han etal., 2009). Chronic stimulation of $\beta$-cells with high glucose concentrations might impose insurmountable levels of ER stress and promote the shift from a protective response (Xbp1 splicing and up-regulation of chaperones) to a deleterious response (RIDD and degradation of insulin). Supporting this hypothesis, islets from mice heterozygous for Ire $1 \alpha$ are more resistant to chronic high glucose and had higher gene expression for both Insulin 1 and Insulin 2 (Lipson et al., 2008). Deletion of Ire1 may be beneficial in the case of diabetes type II models.

Maturation of insulin is also inefficient in $\beta$-cells deficient for Xbp1 due in part to RIDD. Ire $1 \alpha$ is activated by Xbp 1 silencing in Min6 insulinoma cells and activated Ire1 $\alpha$ reduces the levels of components of the insulin secretory pathway, namely PC1, PC2, and CPE enzymes, by cleaving the respective mRNAs (Lee et al., 2011). Xbp1 deficient islets of the pancreas present morphological abnormalities, including disorganized structure, few insulin granules, and distended ER, consistent with $\mathrm{Xbp} 1$ being required for expression of ER chaperone genes such as BiP (Hspa5), ERdj4 (Dnajb9), and p58IPK (Dnajc3; Lee et al., 2011).

Regulated Ire1-dependent decay was also associated with innate and adaptive immunity. Ire1 is activated by binding part of the cholera toxin to induce an inflammatory response (Cho et al., 2013). In this case, Xbp 1 is dispensable for signaling but RIDD is required for the activation of RIG-1 (retinoic acid inducible gene 1), NF-kB and interferon pathways (Cho et al., 2013). RIDD is necessary in $\mathrm{CD} 8 \alpha^{+}$dendritic cells for cross-presentation of cell-derived antigens via MHC-class I to CD8+ T cells (Osorio et al., 2014). Xbp1 is necessary to maintain a normal morphology of the ER in $\mathrm{CD} 8 \alpha^{+}$conventional dendritic cells, whereas RIDD has a critical function in regulating the expression of 
integrins and components of the major histocompatibility complex class I antigen-presentation machinery in these cells (Osorio et al., 2014). Moreover, RIDD is also active in B cells, where it cleaves the mRNA of secretory $\mu$ chains (Benhamron et al., 2014).

Regulated Ire1-dependent decay has an essential role in the differentiation of the photoreceptor cells in Drosophila to maintain the homeostasis of the secretory pathway during the morphogenesis of the light gathering organelle, the rhabdomere, which depends on the massive synthesis of membrane and proteins during the second half of pupal development (Coelho et al., 2013). Ire1 mutant photoreceptors show a very dramatic phenotype with atrophy of the rhabdomeres and collapse of the interrhabdomeral space (caused by a defect in the delivery of Rhodopsin 1 and spacemaker protein, respectively), resulting in progressive degeneration of the retina in adult flies (Coelho et al., 2013). Remarkably, Xbp1 mutant photoreceptors show rhabdomeres with almost a normal morphology, evidencing Xbp1-independent roles of Ire1 in this specific biological context (Coelho et al., 2013). RIDD is activated in the Drosophila photoreceptors and promotes the degradation of several mRNA substrates (Figure 2), among them Fatp (Fatty acid transport protein), a previously described regulator of Rhodopsin 1 levels in photoreceptor cells (Dourlen et al., 2012). Fatp mediates the uptake of fatty acids into cells and fatty acids are precursors for the biosynthesis of

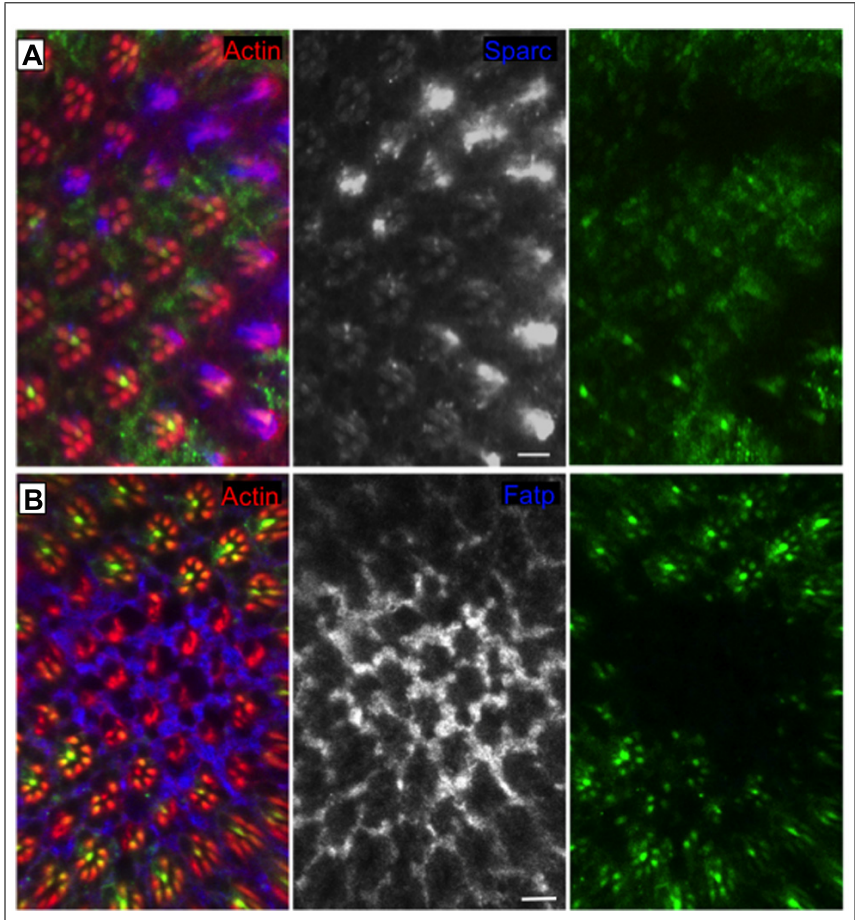

FIGURE 2 | RIDD “in action" in the Drosophila eye. Clones of cells homozygous for Ire1 mutant chromosome (PBac $\left.\{W H\} \mid r e 1^{\mathrm{f0}}{ }^{2170}\right)$ are labeled by the absence of myrGFP. The protein levels of (A) Sparc (blue and monochrome) and (B) Fatp (blue and monochrome) are elevated in Ire1 mutant tissue, in comparison with the surrounding control tissue. Sparc and Fatp are two RIDD substrates in the Drosophila eye. Actin is in red. Scale bars represent $10 \mu \mathrm{m}$. Adapted from Coelho et al. (2013). phosphatic acids. Increased levels of phosphatic acids were previously shown to disrupt rhabdomere morphogenesis (Raghu et al., 2009), causing a phenotype very similar to the one of Ire1 mutant photoreceptors.

Under conditions of overwhelming ER stress induction or chronic low level stress mRNAs encoding secretory cargo proteins and secretory pathway resident proteins start to decay (Han et al., 2009). Indeed, ER chaperone BiP and Golgi-localized glycosylating enzyme Gyltl1b are targets of RIDD. Unmitigated ER stress may deplete important cell surface proteins or secretory pathway proteins by continuous decay and promote apoptosis. Expression of wild-type Ire1 in $\mathrm{Xbp}^{-/}$- MEF triggers apoptosis, but expression of a Ire1 kinase active/RNase dead mutant does not induce apoptosis, arguing that an active RNase is required to induce pro-apoptotic signals independent of Xbp1 mRNA splicing (Han et al., 2009). Indeed, RIDD can also promote the cleavage of selected microRNAs (miRs - 17, 34a, 96, 125b) that normally repress translation of Caspase 2, to control induction of apoptosis upon continued ER stress (Upton et al., 2012).

The two Ire1 functions, RIDD and splicing of Xbp1 mRNA, can be uncoupled in vitro, allowing a better understanding of the physiological output of each pathway. The Ire $1^{\mathrm{I} 42 \mathrm{G}}$ mutant has an enlarged kinase pocket that prevents autophosphorylation and activation of the RNase. The need for ATP binding can be bypassed by incubation with 1NM-PP1, an ATP analog that binds specifically to the designed pocket of Ire $1^{\mathrm{I} 642 \mathrm{G}}$ and activates the RNase by an allosteric mechanism (Papa et al., 2003; Hollien et al., 2009). Addition of the 1NM-PP1 is sufficient to induce Xbp1 splicing when Ire $1^{\mathrm{I}} 642 \mathrm{G}$ is over-expressed, even in the absence of ER stress. However, RIDD function can only be engaged by 1NMPP1 in the presence of ER stress, suggesting different activation modes of Ire1 (Han et al., 2009; Hollien et al., 2009). Other compounds, known as KIRAs (kinase inhibiting RNase attenuators) can bypass the need for autophosphorylation to activate wild-type Ire1, stimulating Xbp1 splicing, and tempering RIDD (Han et al., 2009).

\section{CONCLUSION}

A variety of recent articles demonstrated that RIDD has several physiological roles in different experimental conditions and paradigms. In most cases, RIDD couples the load of ER targeted mRNAs with the ER folding capacity, maintaining the ER homeostasis during cell differentiation and ER expansion. In cases of extreme ER stress, RIDD may trigger apoptosis since it can promote the degradation of ER resident proteins and de-repress Caspase 2. As always, questions remain and should be addressed by additional studies. For example, is it possible to control the RIDD vs. Xbpl splicing activities of Ire1 or to control the substrate specificity of RIDD to cause different biological outcomes? Stay tuned for further developments.

\section{REFERENCES}

Acosta-Alvear, D., Zhou, Y., Blais, A., Tsikitis, M., Lents, N. H., Arias, C., et al. (2007). $\mathrm{XBP} 1$ controls diverse cell type- and condition-specific transcriptional regulatory networks. Mol. Cell 27, 53-66. doi: 10.1016/j.molcel.2007.06.011

Aragón, T., van Anken, E., Pincus, D., Serafimova, I. M., Korennykh, A. V., Rubio, C. A., et al. (2009). Messenger RNA targeting to endoplasmic reticulum stress signalling sites. Nature 457, 736-740. doi: 10.1038/nature07641 
Benhamron, S., Hadar, R., Iwawaky, T., So, J.-S., Lee, A.-H., and Tirosh, B. (2014). Regulated IRE1-dependent decay participates in curtailing immunoglobulin secretion from plasma cells. Eur. J. Immunol. 44, 867-876. doi: 10.1002/eji.201343953

Calfon, M., Zeng, H., Urano, F., Till, J. H., Hubbard, S. R., Harding, H. P., et al. (2002). IRE1 couples endoplasmic reticulum load to secretory capacity by processing the XBP-1 mRNA. Nature 415, 92-96. doi: 10.1038/415092a

Chapman, R. E., and Walter, P. (1997). Translational attenuation mediated by an mRNA intron. Curr. Biol. 7, 850-859. doi: 10.1016/S0960-9822(06)00373-3

Cho, J. A., Lee, A.-H., Platzer, B., Cross, B. C. S., Gardner, B. M., De Luca, H., et al. (2013). The unfolded protein response element IRE1 $\alpha$ senses bacterial proteins invading the ER to activate RIG-I and innate immune signaling. Cell Host Microbe 13, 558-569. doi: 10.1016/j.chom.2013.03.011

Claessen, J. H. L., Kundrat, L., and Ploegh, H. L. (2012). Protein quality control in the ER: balancing the ubiquitin checkbook. Trends Cell Biol. 22, 22-32. doi: 10.1016/j.tcb.2011.09.010

Coelho, D. S., Cairrão, F., Zeng, X., Pires, E., Coelho, A. V., Ron, D., et al. (2013). Xbpl-independent irel signaling is required for photoreceptor differentiation and rhabdomere morphogenesis in Drosophila. Cell Rep. 5, 791-801. doi: 10.1016/j.celrep.2013.09.046

Cooper, G. M. (2000). The Cell: A Molecular Approach. Washington, DC; Sunderland, MA: ASM Press; Sinauer Associates.

Cox, J. S., Shamu, C. E., and Walter, P. (1993). Transcriptional induction of genes encoding endoplasmic reticulum resident proteins requires a transmembrane protein kinase. Cell 73, 1197-1206. doi: 10.1016/0092-8674(93)90648-A

Cox, J. S., and Walter, P. (1996). A novel mechanism for regulating activity of a transcription factor that controls the unfolded protein response. Cell 87, 391-404. doi: 10.1016/S0092-8674(00)81360-4

Cross, B. C., Bond, P. J., Sadowski, P. G., Jha, B. K., Zak, J., Goodman, J. M., et al. (2012). The molecular basis for selective inhibition of unconventional mRNA splicing by an IRE1-binding small molecule. Proc. Natl. Acad. Sci. U. S. A. 109, E869-E878. doi: 10.1073/pnas.1115623109

Dourlen, P., Bertin, B., Chatelain, G., Robin, M., Napoletano, F., Roux, M. J., et al. (2012). Drosophila fatty acid transport protein regulates rhodopsin-1 metabolism and is required for photoreceptor neuron survival. PLoS Genet. 8:e1002833. doi: 10.1371/journal.pgen.1002833

Gaddam, D., Stevens, N., and Hollien, J. (2013). Comparison of mRNA localization and regulation during endoplasmic reticulum stress in Drosophila cells. Mol. Biol. Cell 24, 14-20. doi: 10.1091/mbc.E12-06-0491

Gardner, B. M., Pincus, D., Gotthardt, K., Gallagher, C. M., and Walter, P. (2013). Endoplasmic reticulum stress sensing in the unfolded protein response. Cold Spring Harb. Perspect. Biol. 5:a013169. doi: 10.1101/cshperspect.a013169

Han, D., Lerner, A. G., Vande Walle, L., Upton, J.-P., Xu, W., Hagen, A., et al. (2009). IRElalpha kinase activation modes control alternate endoribonuclease outputs to determine divergent cell fates. Cell 138, 562-575. doi: 10.1016/j.cell.2009. 07.017

Harding, H. P., Calfon, M., Urano, F., Novoa, I., and Ron, D. (2002). Transcriptional and translational control in the Mammalian unfolded protein response. Annu. Rev. Cell Dev. Biol. 18, 575-599. doi: 10.1146/annurev.cellbio.18.011402.160624

He, Y., Beatty, A., Han, X., Ji, Y., Ma, X., Adelstein, R. S., et al. (2012). Nonmuscle myosin IIB links cytoskeleton to IRE1 $\alpha$ signaling during ER stress. Dev. Cell 23 , 1141-1152. doi: 10.1016/j.devcel.2012.11.006

Hetz, C. (2012). The unfolded protein response: controlling cell fate decisions under ER stress and beyond. Nat. Rev. Mol. Cell Biol. 13, 89-102. doi: 10.1038/nrm3270

Hetz, C., and Glimcher, L. H. (2009). Fine-tuning of the unfolded protein response: assembling the IRElalpha interactome. Mol. Cell 35, 551-561. doi: 10.1016/j.molcel.2009.08.021

Hollien, J. (2013). Evolution of the unfolded protein response. Biochim. Biophys. Acta 1833, 2458-2463. doi: 10.1016/j.bbamcr.2013.01.016

Hollien, J., Lin, J. H., Li, H., Stevens, N., Walter, P., and Weissman, J. S. (2009). Regulated Ire1-dependent decay of messenger RNAs in mammalian cells. J. Cell Biol. 186, 323-331. doi: 10.1083/jcb.200903014

Hollien, J., and Weissman, J. S. (2006). Decay of endoplasmic reticulum-localized mRNAs during the unfolded protein response. Science 313, 104-107. doi: $10.1126 /$ science. 1129631

Hur, K. Y., So, J.-S., Ruda, V., Frank-Kamenetsky, M., Fitzgerald, K., Koteliansky, V., et al. (2012). IRE1 $\alpha$ activation protects mice against acetaminophen-induced hepatotoxicity. J. Exp. Med. 209, 307-318. doi: 10.1084/jem.20111298
Iqbal, J., Dai, K., Seimon, T., Jungreis, R., Oyadomari, M., Kuriakose, G., et al. (2008). IRE1 $\beta$ inhibits chylomicron production by selectively degrading MTP mRNA. Cell Metab. 7, 445-455. doi: 10.1016/j.cmet.2008.03.005

Kimmig, P., Diaz, M., Zheng, J., Williams, C. C., Lang, A., Aragón, T., et al. (2012). The unfolded protein response in fission yeast modulates stability of select mRNAs to maintain protein homeostasis. Elife 1:e00048. doi: 10.7554/eLife.00048

Koizumi, N., Martinez, I. M., Kimata, Y., Kohno, K., Sano, H., and Chrispeels, M. J. (2001). Molecular characterization of two Arabidopsis Irel homologs, endoplasmic reticulum-located transmembrane protein kinases. Plant Physiol. 127, 949-962. doi: 10.1104/pp.010636

Korennykh, A. V., Egea, P. F., Korostelev, A. A., Finer-Moore, J., Zhang, C., Shokat, K. M., et al. (2009). The unfolded protein response signals through high-order assembly of Ire1. Nature 457, 687-693. doi: 10.1038/nature07661

Korennykh, A. V., Egea, P. F., Korostelev, A. A., Finer-Moore, J., Stroud, R. M., Zhang, C., et al. (2011a). Cofactor-mediated conformational control in the bifunctional kinase/RNase Ire1. BMC Biol. 9:48. doi: 10.1186/1741-7007-9-48

Korennykh, A. V., Korostelev, A. A., Egea, P. F., Finer-Moore, J., Stroud, R. M., Zhang, C., et al. (2011b). Structural and functional basis for RNA cleavage by Ire1. BMC Biol. 9:47. doi: 10.1186/1741-7007-9-47

Korennykh, A., and Walter, P. (2012). Structural basis of the unfolded protein response. Annu. Rev. Cell Dev. Biol. 28, 251-277. doi: 10.1146/annurev-cellbio101011-155826

Lee, A.-H., Heidtman, K., Hotamisligil, G. S., and Glimcher, L. H. (2011). Dual and opposing roles of the unfolded protein response regulated by IRE1 and XBP1 in proinsulin processing and insulin secretion. Proc. Natl. Acad. Sci. U.S.A. 108, 8885-8890. doi: 10.1073/pnas.1105564108

Lee, A.-H., Iwakoshi, N. N., and Glimcher, L. H. (2003). XBP-1 regulates a subset of endoplasmic reticulum resident chaperone genes in the unfolded protein response. Mol. Cell. Biol. 23, 7448-7459. doi: 10.1128/MCB.23.21.74487459.2003

Lee, K. P. K., Dey, M., Neculai, D., Cao, C., Dever, T. E., and Sicheri, F. (2008). Structure of the dual enzyme Irel reveals the basis for catalysis and regulation in nonconventional RNA splicing. Cell 132, 89-100. doi: 10.1016/j.cell.2007.10.057

Lipson, K. L., Ghosh, R., and Urano, F. (2008). The role of IRE1 $\alpha$ in the degradation of insulin mRNA in pancreatic $\beta$-Cells. PLoS ONE 3:e1648. doi: 10.1371/journal.pone.0001648

Liu, C. Y., Schröder, M., and Kaufman, R. J. (2000). Ligand-independent dimerization activates the stress response kinases IRE1 and PERK in the lumen of the endoplasmic reticulum. J. Biol. Chem. 275, 24881-24885. doi: 10.1074/jbc.M004454200

Marciniak, S. J., and Ron, D. (2006). Endoplasmic reticulum stress signaling in disease. Physiol. Rev. 86, 1133-1149. doi: 10.1152/physrev.00015.2006

Mauro, C., Crescenzi, E., De Mattia, R., Pacifico, F., Mellone, S., Salzano, S., et al. (2006). Central role of the scaffold protein tumor necrosis factor receptorassociated factor 2 in regulating endoplasmic reticulum stress-induced apoptosis. J. Biol. Chem. 281, 2631-2638. doi: 10.1074/jbc.M502181200

Moore, K. A., and Hollien, J. (2012). The unfolded protein response in secretory cell function. Annu. Rev. Genet. 46, 165-183. doi: 10.1146/annurev-genet-110711155644

Moore, K. A., Plant, J. J., Gaddam, D., Craft, J., and Hollien, J. (2013). Regulation of sumo mRNA during endoplasmic reticulum stress. PLoS ONE 8:e75723. doi: 10.1371/journal.pone. 0075723

Mori, K., Ma, W., Gething, M. J., and Sambrook, J. (1993). A transmembrane protein with a cdc2+/CDC28-related kinase activity is required for signaling from the ER to the nucleus. Cell 74, 743-756. doi: 10.1016/0092-8674(93)90521-Q

Mori, K., Kawahara, T., Yoshida, H., Yanagi, H., and Yura, T. (1996). Signalling from endoplasmic reticulum to nucleus: transcription factor with a basic-leucine zipper motif is required for the unfolded protein-response pathway. Genes Cells 1, 803-817. doi: 10.1046/j.1365-2443.1996.d01-274.x

Mori, K., Sant, A., Kohno, K., Normington, K., Gething, M. J., and Sambrook, J. F. (1992). A 22 bp cis-acting element is necessary and sufficient for the induction of the yeast KAR2 (BiP) gene by unfolded proteins. EMBO J. 11, 2583-2593.

Nagai, A., Kadowaki, H., Maruyama, T., Takeda, K., Nishitoh, H., and Ichijo, H. (2009). USP14 inhibits ER-associated degradation via interaction with IRE1alpha. Biochem. Biophys. Res. Commun. 379, 995-1000. doi: 10.1016/j.bbrc.2008.12.182

Nikawa, J., Akiyoshi, M., Hirata, S., and Fukuda, T. (1996). Saccharomyces cerevisiae IRE2/HAC1 is involved in IRE1-mediated KAR2 expression. Nucleic Acids Res. 24, 4222-4226. doi: 10.1093/nar/24.21.4222 
Nishitoh, H., Matsuzawa, A., Tobiume, K., Saegusa, K., Takeda, K., Inoue, K., et al. (2002). ASK1 is essential for endoplasmic reticulum stress-induced neuronal cell death triggered by expanded polyglutamine repeats. Genes Dev. 16, 1345-1355. doi: 10.1101/gad.992302

Ogata, M., Hino, S., Saito, A., Morikawa, K., Kondo, S., Kanemoto, S., et al. (2006). Autophagy is activated for cell survival after endoplasmic reticulum stress. Mol. Cell. Biol. 26, 9220-9231. doi: 10.1128/MCB.01453-06

Oikawa, D., Tokuda, M., Hosoda, A., and Iwawaki, T. (2010). Identification of a consensus element recognized and cleaved by IRE1. Nucleic Acids Res. 38, 62656273. doi: 10.1093/nar/gkq452

Osorio, F., Tavernier, S. J., Hoffmann, E., Saeys, Y., Martens, L., Vetters, J., et al. (2014). The unfolded-protein-response sensor IRE- $1 \alpha$ regulates the function of CD8 ${ }^{\alpha+}$ dendritic cells. Nat. Immunol. 15, 248-257.

Papa, F. R., Zhang, C., Shokat, K., and Walter, P. (2003). Bypassing a kinase activity with an ATP-competitive drug. Science 302, 1533-1537. doi: $10.1126 /$ science. 1090031

Pattingre, S., Bauvy, C., Carpentier, S., Levade, T., Levine, B., and Codogno, P. (2009). Role of JNK1-dependent Bcl-2 phosphorylation in ceramide-induced macroautophagy. J. Biol. Chem. 284, 2719-2728. doi: 10.1074/jbc.M805920200

Raghu, P., Coessens, E., Manifava, M., Georgiev, P., Pettitt, T., Wood, E., et al. (2009). Rhabdomere biogenesis in Drosophila photoreceptors is acutely sensitive to phosphatidic acid levels. J. Cell Biol. 185, 129-145. doi: 10.1083/jcb.200807027

Rasheva, V. I., and Domingos, P. M. (2009). Cellular responses to endoplasmic reticulum stress and apoptosis. Apoptosis 14, 996-1007. doi: 10.1007/s10495009-0341-y

Ron, D., and Walter, P. (2007). Signal integration in the endoplasmic reticulum unfolded protein response. Nat. Rev. Mol. Cell Biol. 8, 519-529. doi $10.1038 / \mathrm{nrm} 2199$

Rüegsegger, U., Leber, J. H., and Walter, P. (2001). Block of HACl mRNA translation by long-range base pairing is released by cytoplasmic splicing upon induction of the unfolded protein response. Cell 107, 103-114. doi: 10.1016/S0092-8674(01)00505-0

Shaffer, A. L., Shapiro-Shelef, M., Iwakoshi, N. N., Lee, A.-H., Qian, S.-B., Zhao, H., et al. (2004). XBP1, downstream of Blimp-1, expands the secretory apparatus and other organelles, and increases protein synthesis in plasma cell differentiation. Immunity 21, 81-93. doi: 10.1016/j.immuni.2004.06.010

Shamu, C. E., and Walter, P. (1996). Oligomerization and phosphorylation of the Irelp kinase during intracellular signaling from the endoplasmic reticulum to the nucleus. EMBO J. 15, 3028-3039.

Shen, X., Ellis, R. E., Lee, K., Liu, C. Y., Yang, K., Solomon, A., et al. (2001). Complementary signaling pathways regulate the unfolded protein response and are required for C. elegans development. Cell 107, 893-903. doi: 10.1016/S00928674(01)00612-2

Shen, X., Ellis, R. E., Sakaki, K., and Kaufman, R. J. (2005). Genetic interactions due to constitutive and inducible gene regulation mediated by the unfolded protein response in C. elegans. PLoS Genet. 1:e37. doi: 10.1371/journal.pgen.0010037

Shoulders, M. D., Ryno, L. M., Genereux, J. C., Moresco, J. J., Tu, P. G., Wu, C., et al. (2013). Stress-independent activation of XBP1s and/or ATF6 reveals three functionally diverse ER proteostasis environments. Cell Rep. 3, 1279-1292. doi: 10.1016/j.celrep.2013.03.024

Sidrauski, C., Cox, J. S., and Walter, P. (1996). tRNA ligase is required for regulated mRNA splicing in the unfolded protein response. Cell 87, 405-413. doi: 10.1016/S0092-8674(00)81361-6

Sidrauski, C., and Walter, P. (1997). The transmembrane kinase Irelp is a site-specific endonuclease that initiates mRNA splicing in the unfolded protein response. Cell 90, 1031-1039. doi: 10.1016/S0092-8674(00)80369-4

Smith, M. H., Ploegh, H. L., and Weissman, J. S. (2011). Road to ruin: targeting proteins for degradation in the endoplasmic reticulum. Science 334, 1086-1090. doi: $10.1126 /$ science. 1209235
So, J.-S., Hur, K. Y., Tarrio, M., Ruda, V., Frank-Kamenetsky, M., Fitzgerald, K., et al. (2012). Silencing of lipid metabolism genes through IRE1 $\alpha$-mediated mRNA decay lowers plasma lipids in mice. Cell Metab. 16, 487-499. doi: 10.1016/j.cmet.2012.09.004

Tirasophon, W., Welihinda, A. A., and Kaufman, R. J. (1998). A stress response pathway from the endoplasmic reticulum to the nucleus requires a novel bifunctional protein kinase/endoribonuclease (Irelp) in mammalian cells. Genes Dev. 12, 1812-1824. doi: 10.1101/gad.12.12.1812

Tsuru, A., Fujimoto, N., Takahashi, S., Saito, M., Nakamura, D., Iwano, M., et al. (2013). Negative feedback by IRE1 optimizes mucin production in goblet cells. Proc. Natl. Acad. Sci. U.S.A. 110, 2864-2869. doi: 10.1073/pnas.1212484110

Upton, J.-P., Wang, L., Han, D., Wang, E. S., Huskey, N. E., Lim, L., et al. (2012). IRE $1 \alpha$ cleaves select microRNAs during ER stress to derepress translation of proapoptotic Caspase-2. Science 338, 818-822. doi: 10.1126/science. 1226191

Urano, F., Wang, X., Bertolotti, A., Zhang, Y., Chung, P., Harding, H. P., etal. (2000). Coupling of stress in the ER to activation of JNK protein kinases by transmembrane protein kinase IRE1. Science 287, 664-666. doi: 10.1126/science.287.5453.664

Wang, S., and Kaufman, R. J. (2012). The impact of the unfolded protein response on human disease. J. Cell Biol. 197, 857-867. doi: 10.1083/jcb.201110131

Wang, X. Z., Harding, H. P., Zhang, Y., Jolicoeur, E. M., Kuroda, M., and Ron, D. (1998). Cloning of mammalian Irel reveals diversity in the ER stress responses. EMBO J. 17, 5708-5717. doi: 10.1093/emboj/17.19.5708

Welihinda, A. A., and Kaufman, R. J. (1996). The unfolded protein response pathway in Saccharomyces cerevisiae. Oligomerization and trans-phosphorylation of Irelp (Ernlp) are required for kinase activation. J. Biol. Chem. 271, 18181-18187. doi: 10.1074/jbc.271.30.18181

Yanagitani, K., Imagawa, Y., Iwawaki, T., Hosoda, A., Saito, M., Kimata, Y., et al. (2009). Cotranslational targeting of XBP1 protein to the membrane promotes cytoplasmic splicing of its own mRNA. Mol. Cell 34, 191-200. doi: 10.1016/j.molcel.2009.02.033

Yanagitani, K., Kimata, Y., Kadokura, H., and Kohno, K. (2011). Translational pausing ensures membrane targeting and cytoplasmic splicing of XBP1u mRNA. Science 331, 586-589. doi: 10.1126/science.1197142

Yoshida, H., Matsui, T., Yamamoto, A., Okada, T., and Mori, K. (2001). XBP1 mRNA is induced by ATF6 and spliced by IRE1 in response to ER stress to produce a highly active transcription factor. Cell 107, 881-891. doi: 10.1016/S0092-8674(01)00611-0

Yoshida, H., Oku, M., Suzuki, M., and Mori, K. (2006). pXBP1(U) encoded in XBP1 pre-mRNA negatively regulates unfolded protein response activator pXBP1(S) in mammalian ER stress response. J. Cell Biol. 172, 565-575. doi: $10.1083 /$ jcb. 200508145

Conflict of Interest Statement: The authors declare that the research was conducted in the absence of any commercial or financial relationships that could be construed as a potential conflict of interest.

Received: 20 February 2014; accepted: 24 March 2014; published online: 16 April 2014. Citation: Coelho DS and Domingos PM (2014) Physiological roles of regulated Ire1 dependent decay. Front. Genet. 5:76. doi: 10.3389/fgene.2014.00076

This article was submitted to Genomic Endocrinology, a section of the journal Frontiers in Genetics.

Copyright (C) 2014 Coelho and Domingos. This is an open-access article distributed under the terms of the Creative Commons Attribution License (CC BY). The use, distribution or reproduction in other forums is permitted, provided the original author(s) or licensor are credited and that the original publication in this journal is cited, in accordance with accepted academic practice. No use, distribution or reproduction is permitted which does not comply with these terms. 